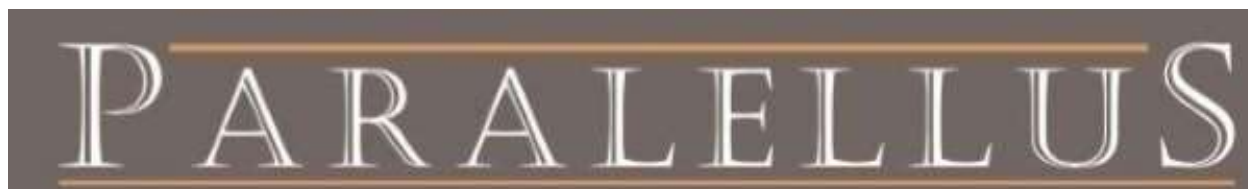

REVISTA ELETRÔNICA EM CIÊNCIAS DA RELIGIÃO - UNICAP

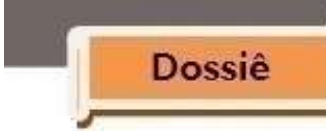

\title{
A JANGADA DO SELF: USOS SOTERIOLÓGICOS DO EU E DO NÃO- EU NO BUDDHISMO ANTIGO
}

\author{
THE RAFT OF THE SELF: SOTERIOLOGICAL USES OF SELF AND NOT- \\ SELF IN ANCIENT BUDDHISM
}

Felipe Nogueira de Carvalho*

\section{RESUMO}

O objetivo deste artigo é sugerir que os ensinamentos Buddhistas sobre anattā (não-eu) não devem ser entendidos como uma negação categórica do eu, mas fazem parte de uma estratégia soteriológica comumente empregada pelo Buddha, de utilizar algo como ferramenta para o seu próprio fim. Tomando o kamma (ação) como o elemento central que estrutura todos os ensinamentos, podemos pensar na identificação do eu como um tipo de ação. Algumas instâncias desta ação serão hábeis e condutoras à libertação, e outras inábeis e condutoras ao sofrimento.Com isso em mente, este artigo irá analisar algumas ações inábeis do eu e do não-eu em suttas selecionados do Cânone Pali, mostrando como se encaixam na estratégia do Buddha de se utilizar de elementos como ferramentas para o abandono desses próprios elementos. Nessa perspectiva, o eu não é negado em absoluto desde o início do caminho, mas aprende-se a usá-lo de forma hábil como um meio de abandoná-lo.

Palavras-chave: Buddhismo antigo; Cânone Pali; Não-eu; Soteriologia.

\footnotetext{
* Doutor em Filosofia pela École des Hautes Études en Sciences Sociales (Paris, França). Pesquisador pós-doutor pelo programa Capes-PrInt no Departamento de Filosofia da Universidade Federal de Minas Gerais. E-mail: felipencarvalho@gmail.com. Lattes: http://lattes.cnpq.br/9934624315948836. Orcid iD: http://orcid.org/0000-0002-0584-3424.
} 


\section{ABSTRACT}

The purpose of this article is to suggest that the Buddhist teachings on anattā (not-self) should not be understood as a categorical denial of the self, but constitute a soteriological strategy commonly employed by the Buddha, of using something as tool for its own demise.Taking kamma (action) as the main framework that structure all the other teachings, we can think of self-identification as a kind of action. Some instances of this action will be skillful and will lead to liberation, while others will be unskillful and will lead to suffering.With this in mind, the present article will analyze some skillful actions of self and not-self in selected suttas of the Pali canon, showing how they fit into the Buddha's overall strategy of using elements as tools for their own demise. In this perspective, the self is not denied from the beginning of the path, but one learns how to use it skillfully in order to let go of it.

Keywords: Ancient Buddhism; Pali canon; Not-self; Soteriology.

\section{INTRODUÇÃO}

Os ensinamentos Buddhistas sobre anattā ("não-eu") são ao mesmo tempo os aspectos mais importantes e difíceis de serem compreendidos de todo o Buddhismo. Se comparada às outras duas característica universais da existência, anicca (impermanência) e dukkha (insatisfatoriedade), cuja verificação pela experiência direta é significativamente mais simples, anattā pode se mostrar como algo obscuro e contra-intuitivo. A ideia de que o eu estável e unificado com o qual estamos familiarizados em nossa experiência mundana, possa não existir como algo distinto de uma série de processos e disposições mentais em constante fluxo e movimento, ainda soa estranha para boa parte dos ouvidos não-buddhistas. Mas todo o caminho Buddhista de libertação do sofrimento parece culminar exatamente nesse ponto, na total desidentificação com qualquer coisa que possa ser chamada de "eu" ou "meu". Sem a realização completa e absoluta de anattā não há libertação possível, como Nyanatiloka Mahathera coloca contundentemente:

Sem a compreensão da ausência de eu da existência, não é possível adquirir uma compreensão real da palavra do Buddha; e não é possível realizar o objetivo de emancipação e libertação da mente proclamados pelo Buddha. (...) Sem os ensinamentos sobre anattā, ou não-eu, não existe Buddhismo; e sem realizar a verdade do não-eu não pode haver progresso real no caminho para a libertação. (MAHATHERA; Nyanatiloka, 1957, p. 2-3)

Mas ao mesmo tempo em que anattā é o pilar central do caminho Buddhista, é algo ainda difícil de ser compreendido em todas as suas implicações. Claro, de um ponto 
de vista meramente teórico é simples entender o significado de anattā no contexto da visão de mundo Buddhista. O Buddhismo concebe o mundo e os seres que o habitam como uma imensa e complexa rede de processos dinâmicos interconectados, sem postular, para cada ser sensível, uma entidade estável guiando esses processos a partir do interior. A conclusão óbvia desta visão de mundo é que há pouco lugar para uma identidade estável interior que podemos chamar de "eu". Se temos a experiência de um eu interior estável, esta experiência deve ser uma ilusão, provinda de uma aplicação enganosa da permanência e estabilidade a fenômenos que são em si impermanentes e instáveis.

Mas se a experiência do eu é uma ilusão, ela é sem dúvida uma ilusão teimosamente persistente. No nível da experiência mundana, parece que temos um núcleo central interior, a voz dentro de nós que planeja, pensa e executa ações no mundo, que nos acompanha fielmente durante os diversos estágios da nossa vida, a nossa identidade verdadeira que apenas nós conhecemos. $O$ fato de podermos rememorar e simular nossos estados mentais e emocionais do passado, nos dá a impressão de um eu interior que, através de todas as nossas mudanças físicas e psicológicas durante a vida, permanece o mesmo. E por mais que possamos decompor analiticamente nossa vida interior em termos dos agregados mentais descritos pelo Buddha1, parece que há algo além dos agregados que foi deixado de lado nessa decomposição.

Conta-se no Khemaka Sutta que o Venerável Khemaka, um monge ancião, quando questionado se já era um arahant, um iluminado, respondeu categoricamente que não; pois embora já tivesse compreendido os agregados e não se identificasse mais com eles, ainda detectava em si um resquício residual e não-conceitual do "eu sou":

Não é que eu diga "Eu sou forma", nem diga "Eu sou sensação....percepção...fabricações mentais... consciência," nem diga "Eu sou algo diferente da consciência". Em relação aos cinco agregados do apego "Eu sou" ainda não foi superado, embora eu não presuma que "Eu sou isto" (SN 22:89)2.

1 São eles: o agregado da sensação (vedanākhandha), o agregado da percepção (sañnākhandha), o agregado das fabricações mentais (samkhārakhandha) e o agregado da consciência (viñnnākhandha). Além destes quatro agregados mentais, o agregado da forma (rūpakhandha) completa os cinco agregados do apego.

2 Todos os suttas foram traduzidos a partir de Thānissaro Bhikkhu (2014). 
O que Khemaka diz nesta passagem é que a experiência subjetiva vai além da composição de suas partes, ou seja, o eu da experiência mundana ainda parece ser algo maior que a experiência de cada um dos cinco agregados. Desta forma, mesmo quando a identificação com os agregados é superada, ainda pode haver uma consciência residual do eu que sobrevive a este processo de desidentificação.

Para dificultar ainda mais as coisas, a literatura Buddhista nem sempre é clara sobre como proceder para nos desfazer da identificação com aquilo que experienciamos como nosso eu. Claro que por um lado as instruções não poderiam ser mais claras: através da compreensão das quatro nobres verdades e realização do nobre caminho óctuplo, devemos ser capazes de vencer toda forma de apego e atingir a iluminação. Mas ao mesmo tempo, se, como disse Nyanatiloka Mahathera, "sem realizar a verdade do não-eu não pode haver progresso real no caminho para a libertação", para que possamos começar a trilhar o caminho algum tipo de identificação do eu parece ser requisitado - tanto como o agente que se inicia no caminho e o realiza até o seu fim com diligência e perseverança, como o recipiente do estado de felicidade duradouro que virá com a realização do caminho.

Esse último ponto merece clarificação. O nobre caminho óctuplo se inicia com o discernimento correto, presente nos fatores da perspectiva correta e intenção correta. E uma das maneiras de cultivar o discernimento correto é colocada pelo Buddha em termos das seguintes questões:

Este é o caminho que leva ao discernimento: quando visitar um contemplativo ou um brâmane, pergunte: "O que é benéfico, venerável senhor? O que é prejudicial? O que é condenável? O que não é condenável? O que deve ser cultivado? O que não deve ser cultivado? O que, se eu fizer, será pelo meu sofrimento e prejuízo a longo prazo? Ou o que, se eu fizer, será pela minha felicidade e bem-estar a longo prazo?" (MN 135)

A pergunta "o que, se eu fizer, será pela minha felicidade e bem-estar a longo prazo?" revela ambos os sentidos do eu, como agente (“...se eu fizer...”) e como recipiente (“...pela minha felicidade...”). Quando ponderamos sobre o que fazer, ou o que é correto fazer em cada circunstância, relativos ao nosso objetivo final de libertação do sofrimento, estamos identificando o eu como agente; aquele que possui liberdade de agir da forma correta em cada situação, gerando um kamma que possibilitará o 
objetivo final de se atingir o nibbāna ("eu sou capaz de agir e tenho liberdade para isso"). E quando decidimos agir de determinada maneira em prol da nossa felicidade ${ }^{3}$, estamos identificando o eu como recipiente, aquele que irá adquirir discernimento e sabedoria e se beneficiará das ações tomadas pelo eu como agente ("eu colherei o benefício de minhas próprias ações").

Assim, quando escolhemos em determinada circunstância agir da forma correta mesmo sem ganho imediato - embora tal ganho pudesse ser obtido agindo de forma incorreta - compreendemos o que é abrir mão de algo passageiro e imediato em prol de algo duradouro à longo prazo. Mas para que possamos fazer isso, é preciso que tenhamos ao mesmo tempo um senso de agência - de que somos seres dotados de certo controle e liberdade sobre as escolhas e ações que fazemos - e consciência de nosso papel como beneficiários, ou seja, que seremos nós aqueles a colher mais tarde o benefício dessas ações.

Mas agora parecemos atingir um impasse. Por um lado, ouvimos que toda e qualquer identificação do eu deve ser abandonada, e que não há progresso possível no caminho enquanto houver tal identificação. Mas por outro lado, o caminho para esse abandono parece pedir por um certo tipo de identificação do eu, à medida em que identificamos o eu como agente e recipiente no cultivo do discernimento correto. $\mathrm{O}$ que fazer? A solução para esse aparente impasse está justamente na aceitação desse paradoxo: o uso de um certo tipo de identificação do eu faz parte do caminho que leva ao seu abandono.

\section{A JANGADA DO SELF}

A ideia de se usar um elemento como ferramenta para transcender este próprio elemento é na verdade uma estratégia comumente empregada pelo Buddha ao longo dos suttas. Esta ideia está presente na analogia feita pelo Buddha entre o dhamma e uma jangada a ser utilizada para chegar a outra margem de um rio (MN 2). Embora a

3 O fato de agirmos em prol da nossa felicidade não faz de nós egoístas; uma das coisas que aprendemos ao refletir sobre esta pergunta é justamente como a nossa felicidade está intrinsicamente ligada à felicidade de todos os seres. 
jangada possa nos ter sido útil na travessia, ao atingirmos a outra margem não precisamos mais carregá-la conosco, e devemos deixá-la de lado.

Da mesma forma, o Buddha diz que podemos usar até mesmo fatores mentais negativos como ferramentas para seu próprio fim, como a vaidade e o desejo (AN 4: 159). Quando vemos um(a) companheiro(a) da sańgha avançando no caminho mais rapidamente que nós, podemos usar nossa vaidade e desejo de ser como ele(a) como ferramentas de inspiração e motivação. Uma vez que avancemos na prática, a inveja e o desejo serão gradualmente eliminados. O mesmo acontece com as opiniões. Embora o Buddha diga que aquele que atingiu o nibbāna não se apega a opinião alguma (MN 72), para se chegar a esse estado é preciso se ater a algumas opiniões - a saber, as opiniões que constituem o fator da perspectiva correta do nobre caminho óctuplo. E finalmente, o próprio caminho Buddhista pode ser descrito como a apreensão correta da habilidade de usar o kamma como um modo de extinguir o próprio kamma. Ao compreendermos com maestria as relações de causa e efeito, sabemos como criar ações meritórias e auspiciosas que levam ao nibbāna e ao fim do kamma. O eu seria apenas mais um desses elementos que aprendemos a usar como ferramenta para o seu próprio fim.

Embora Nyanatiloka Mahathera esteja sem dúvida correto ao dizer que sem a realização total de anattā a libertação do sofrimento não é possível, deve-se fazer uma distinção entre diferentes estágios do caminho Buddhista. No fim do caminho, enquanto houver qualquer resquício de identificação com o eu, o praticante jamais chegará ao estado final de arahant (como vimos com o Venerável Khenaka). Mas para aqueles que começam a trilhar o caminho Buddhista, um uso saudável e não-reificado do eu, cultivado de forma correta e sem apego, poderá se mostrar como uma ferramenta valiosa na realização de anattā e libertação final do sofrimento. Esclarecer como cultivar um uso do eu saudável e não-reificado será o tema principal do restante deste artigo.

\section{ANATTĀ NO CONTEXTO DAS QUATRO NOBRES VERDADES}

A seção anterior sugeriu que pode haver uma dimensão de anattā que ultrapassa uma simples negação categórica do eu. Embora em alguns momentos o Buddha pareça 
estar fazendo tal negação - sobretudo no Mahā Nidāna Sutta (DN 15), onde lista diversas maneiras concebíveis de se pensar o eu e as refuta uma a uma - a interpretação desta passagem como uma negação categórica do eu deve ser resistida. Se o Buddha estivesse fazendo tal negação, defenderia a opinião de que "não existe o eu", mas no Sabbāsava Sutta diz explicitamente que tanto afirmar "existe o eu" quanto "não existe o eu" são opiniões que causam sofrimento naquele que as defende (MN 2). Além disso, quando indagado no Ananda Sutta pelo andarilho Vacchagotta se existe ou não o eu, o Buddha simplesmente se recusa a responder de forma categórica (SN 44:10). Essa recusa é importante, e revela o modo como o Buddha sugere que tratemos essa questão.

O Buddha dividiu as questões em quatro tipos diferentes: aquelas que pedem por uma resposta categórica, aquelas que pedem por uma resposta analítica, aquelas que pedem por uma contra-pergunta, e aquelas que devem se deixadas de lado como perguntas inúteis e prejudiciais ao caminho (AN 4:42). Ora, se o Buddha estivesse interessado em negar categoricamente a existência do eu, ele colocaria a questão de Vacchagotta na primeira categoria, e não teria problema algum em respondê-la de forma negativa. Mas ao se negar a respondê-la o Buddha está colocando-a na quarta categoria, e com isso nos dizendo algo importante sobre o modo como devemos tomar os ensinamentos sobre anattā. Em outras palavras, não devemos nos preocupar em defender a não-existência do eu, mas sim refletir sobre o sofrimento ou felicidade que a identificação com o eu pode nos trazer.

No Sabbāsava Sutta o Buddha discorre sobre ideias que são ou não dignas de atenção, e ensina os monges a deixar de lado as indignas. Quando damos atenção à questões indignas tais como "eu existo?"; "eu não existo?"; "o que sou eu?"; "o que eu era no passado?"; "o que serei no futuro?", etc., acabamos sendo levados por opiniões como "acho que possuo um eu interior" ou "acho que o eu interior não existe". E o Buddha descreve tais opiniões como "um emaranhado de opiniões, um deserto de opiniões, uma contorção de opiniões, um grilhão de opiniões." (MN 2). Ou seja, opiniões que nos aprisionam e fazem com que percamos de vista o caminho para a libertação do sofrimento. 
Por outro lado, o Buddha restringe as questões dignas de atenção apenas às quatro nobres verdades: "isto é sofrimento... esta é a origem do sofrimento... esta é a extinção do sofrimento... este é o caminho para a extinção do sofrimento" (MN 2). Como as únicas questões dignas de atenção, as quatro nobres verdades constituem a chave interpretativa de todas as questões tratadas pelo Buddha. Se houver qualquer dúvida sobre como tratar determinada questão, basta colocá-la sob a perspectiva das quatro nobre verdades, e perguntar de que modo esta questão pode contribuir para a realização das tarefas associadas a cada uma delas: a compreensão do sofrimento, o abandono de sua origem, a realização de sua extinção, e o desenvolvimento do caminho para sua extinção.

Para os interesses específicos deste artigo, é sempre no contexto das quatro nobres verdades que os ensinamentos sobre anattā devem ser compreendidos. Portanto, ao invés de questionarmos se existe ou não um eu, ou teorizarmos sobre o que este eu poderia ser, podemos nos perguntar ao invés disso como o eu e o não-eu podem ser usados de forma hábil na realização das tarefas impostas pelas quatro nobres verdades. Caso a identificação do eu não contribua para a realização dessas tarefas, deve ser impiedosamente abandonada e enfraquecida desde o início do caminho como uma ferramenta inútil e estéril. Mas como vimos anteriormente, faz sentido pensar em usos positivos do eu como ferramentas para o seu próprio fim.

Há algumas passagens no cânone Pali que sugerem um papel construtivo para o eu na realização do caminho Buddhista. No Adhipateyya Sutta o Buddha fala de três princípios governantes que ajudam o praticante a se manter no caminho do dhamma, e entre eles encontramos o eu como princípio governante:

O que é o eu como princípio governante? É quando um monge, ao ir para a floresta, aos pés de uma árvore, ou para uma cabana vazia, reflete da seguinte forma: (...) Estou imerso em nascimento, envelhecimento, e morte; em tristeza, lamentação, dor, melancolia, e angústia. Talvez o fim de todo esse sofrimento possa ser discernido. (...) Ele então reflete da seguinte maneira: a energia será despertada em mim sem preguiça; atenção vigilante será estabelecida em mim sem confusão; meu corpo ficará tranquilo e sem perturbações; minha mente ficará concentrada e unificada. Tendo tomado a si mesmo como princípio governante, ele abandona o que é prejudicial e desenvolve o que é benéfico; ele abandona o que é condenável e desenvolve o que não é condenável; ele cuida de si mesmo com pureza. A isso é chamado o eu como princípio governante. (AN 3:40) 
Essa passagem ressalta os sentidos do eu como agente e recipiente vistos anteriormente. Ao refletir sobre nosso infeliz predicamento como seres imersos em dor e sofrimento (o eu como recipiente), isso nos motiva a agir de determinada maneira, isto é, sem preguiça, com atenção, tranquilidade e concentração (o eu como agente), de forma a realizar as tarefas das quatro nobres verdades. Desta forma, o eu torna-se uma importante ferramenta motivacional que nos mantém firmes na prática.

\section{KAMMA E ANATTĀ}

Mas como usar o eu como agente e como recipiente de forma hábil? Na seção I vimos que um modo de se desenvolver o discernimento é através da seguinte pergunta: "O que, se eu fizer, será pela minha felicidade e bem-estar à longo prazo?" Vimos também que a chave interpretativa para entendermos nossa felicidade e bem-estar à longo prazo está nas quatro nobres verdades, como as únicas questões dignas de atenção. Assim, um modo de se reformular a questão seria da seguinte maneira: "o que, se eu fizer, contribuirá para a realização das tarefas associadas à quatro nobres verdades?"

Quando entendemos o caminho em termos dessa pergunta, estamos colocando o foco sobre nossas ações e suas consequências; ou seja, o kamma. De fato, se pensarmos nas quatro tarefas, o kamma oferece uma poderosa ferramenta para nos ajudar a realizá-las na prática. Em primeiro lugar, o kamma é uma ótima maneira de se começar a compreender o que é o sofrimento. Quando agimos de determinado modo e nossa ação é causa de sofrimento em nós ou em terceiros, à medida em que vemos o sofrimento surgir percebemos como ele está intrinsicamente ligado às nossas ações mentais, verbais ou corporais.

Nesse contexto, o próprio apego pode ser compreendido como um tipo de ação. Quando agimos de forma apegada, experimentamos sofrimento. A medida em que vamos dominando essas relações de causa e efeito, percebemos então a origem do sofrimento em nossas próprias ações, e entendemos que para extinguir o sofrimento basta exterminar suas causas. Se ações de apego causam sofrimento, então abandonando o apego abandona-se o sofrimento, realizando assim a segunda e terceira tarefas. E no que diz respeito à quarta tarefa, novamente o kamma será o 
nosso guia para o desenvolvimento do caminho. No Ambalatțhikā Rāhulovāda Sutta, o Buddha dá instruções para seu filho Rahulā sobre como desenvolver e manter a vigilância, em termos das seguintes perguntas:

Sempre que quiser executar alguma ação corporal, deve refletir da seguinte maneira: esta ação corporal que quero executar - causaria aflição em mim mesmo, em outros, ou em ambos? Seria uma ação corporal inábil, com consequências e resultados dolorosos? Se, por reflexão, você concluir que ela causaria aflição em você, em outros, ou em ambos, e que seria uma ação corporal inábil, com consequências e resultados dolorosos, então seria inapropriado cometer qualquer ação corporal desse tipo. (O mesmo conselho então se segue para ações verbais e mentais). (MN 61)

Esse modo de se colocar a pergunta é ainda mais apropriado do que a pergunta do discernimento, pois expande a felicidade de modo a abarcar outros seres além de nós. Se, em cada circunstância em que nos encontrarmos com liberdade de ação, fizermos essas reflexões, elas serão capazes de cobrir todos os três grupos do nobre caminho óctuplo. Ao nos abstermos de ações que causam sofrimento aos outros desenvolvemos o grupo da disciplina moral (fala correta, ação correta e modo de vida correto); ao cultivarmos ações mentais que trazem benefícios para nós mesmos desenvolvemos a concentração correta, enquanto o próprio ato de reflexão suscitado pela pergunta desenvolve o esforço e a vigilância correta (grupo da concentração); finalmente, dentro do contexto do kamma a perspectiva correta nada mais é do que um conjunto de ações mentais hábeis que contribuem para o fim do sofrimento; isto é, um modo de pensar que está firmemente ancorado na realização do caminho e na visão das coisas como realmente são. É o cultivo da perspectiva correta que irá garantir que as ações apropriadas advindas das reflexões acima sejam de fato hábeis.

O kamma pode então ser compreendido como o elemento que estrutura os ensinamentos Buddhistas e a própria prática do caminho. É através da maestria do kamma e das relações de causa e efeito que se realiza as tarefas das quatro nobres verdades (que são em si ações) e se chega à libertação do sofrimento. Nesse contexto, não pensamos em anattā como a negação absoluta do eu, mas sim como um tipo de ação - a identificação do não-eu - e atta como outro tipo de ação - a identificação do eu. E como tipos de ação, são divididas entre hábeis ou inábeis, e podem ser desenvolvidas e aprimoradas pela prática. Mas como toda ação, há um modo correto e um modo incorreto de executá-la, além de um contexto apropriado e 
um propósito digno para sua execução. Se embarcarmos na jangada do dhamma antes de nos encontrarmos dentro do rio, se nos munirmos de remos inadequados, remarmos na direção errada, ou se quisermos atingir a outra margem para invadir as terras dos nativos que ali habitam, não estaremos utilizando esta ferramenta de forma hábil. O mesmo ocorre com o eu e o não-eu.

Mais uma vez, a pergunta do discernimento, compreendida no contexto das quatro nobres verdades, será o nosso princípio governante para a prática. As quatro nobres verdades determinam portanto o propósito nobre de nossa ação, que é a extinção do sofrimento, e toda ação que realizarmos deverá ser pautada por esse fim. E a pergunta do discernimento, feita a cada circunstância em que temos liberdade de ação, nos dirá quais as formas hábeis e os contextos apropriados para executar a ação em questão. Em outras palavras, a pergunta que devemos fazer será: quando a identificação do eu é uma ação apropriada que deve ser executada?

\section{USOS HÁBEIS E INÁBEIS DO EU E DO NÃO-EU}

É comum lermos nos suttas comentários negativos do Buddha em relação à identificação do eu, sobretudo em relação aos agregados do apego. Quando identificamos os agregados da forma, sensação, percepção, fabricações mentais e consciência como sendo o nosso eu, isso é uma perspectiva incorreta contaminada pela ignorância, que será inevitavelmente causa de grande sofrimento e decepção (SN 22:59, SN 41:3, MN 44). Embora aqueles que interpretam anattā como uma negação categórica do eu se apoiem freqüentemente sobre esses suttas, o Buddha aqui está apenas listando ações inábeis de identificação do eu, e sugerindo ações hábeis de identificação do não-eu. Identificar algum dos agregados como sendo o eu seria uma ação inábil, e identificar cada um dos agregados como sendo não-eu seriam ações hábeis.

De um modo geral, sempre que reificamos um uso do eu e concluímos "isto sou eu, isto é meu, este é o meu eu", tal reificação nos levará ao sofrimento, e será uma ação inábil de identificação do eu. Isto implica que devemos desenvolver a vigilância mesmo em relação a usos saudáveis do eu, para que o eu não seja reificado e se torne objeto da opinião "este sou eu, este é o meu eu". Ao invés disso, a idéia aqui é 
utilizar o eu como uma ferramenta, como um suporte para a prática e um princípio governante, e não reificado em uma opinião racional sobre o que seja o eu.

Quando usamos o eu como agente e recipiente estamos falando de uma ação hábil de identificação do eu, desde que ele não seja reificado em um pensamento do tipo "este agente/recipiente sou eu, este é o meu eu". Esse uso do eu pressupõe um senso de agência e uma consciência do nosso papel como recipientes de benefícios, mas não reifica tais papéis em uma entidade estável e permanente. O filósofo Daniel Dennett, um grande crítico da realidade metafísica do eu, compara o eu ao conceito do centro de gravidade de um corpo; algo que utilizamos como uma ferramenta útil para determinados propósitos práticos, sem com isso atribuir realidade a esse ponto abstrato (DENNETT; Daniel, 1992).

De forma semelhante, o eu utilizado dessa maneira funciona como um elemento motivador que nos mantém focados e direcionados no caminho, sendo portanto uma ação hábil relativa à realização das tarefas das quatro nobres verdades. Afinal de contas, o caminho Buddhista exige bastante disciplina e perseverança. Não é um caminho que promete soluções fáceis e rápidas, mas aponta para o horizonte distante do nibbāna como o único refúgio possível de um mundo de alegrias efêmeras, atingido através da progressiva purificação e equilíbrio da mente. Para se percorrer um caminho longo que exige constante vigilância para se manter na direção certa, é preciso um forte fator motivador. Caso contrário, pode-se facilmente perder de vista o destino final e aventurar-se por outras estradas e vias menos árduas. É justamente nesse fator motivador que entra o uso do eu como agente e recipiente. É uma ferramenta útil para se começar a trilhar o caminho e manter-se fiel a ele, mantendo sempre em vista o destino final. É desta forma que podemos utilizar o eu como ferramenta para o seu próprio fim.

Um ótimo exemplo de um uso hábil do eu, como bem observado por Thānissaro Bhikkhu (2010), é o uso que o Buddha faz de sua própria autobiografia como fator motivador e inspirador para àqueles que queiram seguir o mesmo caminho (MN 14, 26, 36). Ao identificar a si mesmo em sua história ("eu fiz isso", "eu pensei desta forma", "isso aconteceu comigo", etc.), o Buddha está identificando o agente e recipiente que são protagonistas de sua biografia, mas essa identificação se dá para 
fins puramente pedagógicos, e não pressupõe nenhuma reificação ou apego com o eu que executa ações ou colhe os benefícios dessas ações. Além de inspirar seus ouvintes a trilhar o mesmo caminho, a autobiografia do Buddha torna-se o exemplo perfeito da estratégia delineada aqui, de usar o kamma e a pergunta do discernimento para se realizar o caminho e as tarefas das quatro nobres verdades. Pois toda a trajetória do Buddha em sua autobiografia é estruturada em torno de perguntas como essa, à medida em que o príncipe Siddhāttha se transforma no iluminado e abençoado Buddha:

\begin{abstract}
Eu pensei: e se eu, com os dentes cerrados e pressionando minha língua contra o céu da boca, abatesse, forçasse e subjugasse minha mente com a minha própria mente? (...) E se eu praticasse a meditação sem respirar? (...) E se eu praticasse mais a meditação sem respirar? (...) E se eu praticasse cortando completamente a alimentação? (...) E se eu comesse só um pouco de comida de cada vez? (...) E se comesse um pouco de comida sólida: arroz e mingau? (MN 36)
\end{abstract}

Após cada uma dessas perguntas, Siddhāttha, o aspirante à iluminação, executa a ação correspondente e relata os resultados obtidos. Se esses resultados o aproximarem do seu objetivo final da libertação do sofrimento, continua a praticar nesta direção. Caso contrário, descarta a ação como inábil e busca algum outro método mais condizente com seu objetivo. É desta forma, através da tentativa e erro e reflexão contínua com base nessas perguntas, que descobre o caminho do meio entre a auto-mortificação e a entrega aos prazeres sensoriais. É somente após ter recuperado sua força física através do caminho do meio que Siddhāttha avança progressivamente pelos sucessivos estágios de concentração e absorção mental até a iluminação e libertação final.

Mas embora o eu possa ser usado de forma hábil durante os primeiros estágios da prática, faz sentido pensar que em estágios mais avançados ele se tornará cada vez menos necessário, até poder ser abandonado por completo. A medida em que dominamos as relações de causa e efeito entre nossas ações e suas consequências, observadas ao longo da prática a cada vez que refletimos sobre a pergunta do discernimento, passamos a colocar o foco mais nas relações de causalidade em si do que no eu como agente e recipiente. Ao observar que determinada ação traz determinado resultado, buscamos ativamente o cultivo desta ação, e não precisamos 
mais fazer a pergunta do discernimento a cada nova circunstância. E como é a própria pergunta que ressalta os sentidos do eu como agente e recipiente, ao deixarmos a pergunta de lado o eu começa a desaparecer gradualmente do foco de nossa consciência, dando lugar apenas à ações benéficas e suas consequências. Neste ponto não precisamos mais usar o eu para compreendermos as relações causais entre ações e seus frutos, ou para apreciarmos os frutos dessas ações. Aprendemos assim a abrir mão desse uso do eu, compreendendo que não precisamos mais usá-lo neste novo estágio do caminho em que nos adentramos.

Ao deixarmos de lado o eu como agente e recipiente, sem apego ou remorso, compreendemos a impermanência do eu, como algo que aparece à medida em que se faz uso dele, mas que desaparece após a conclusão da tarefa. E desta forma o eu como ferramenta começa a perder seu encanto. Afinal, se não precisamos mais dessa ferramenta para cultivarmos ações virtuosas e colhermos seus frutos, talvez possamos realizar também outras tarefas sem ela? Percebemos que construir narrativas tomando o eu como base necessariamente limita essas narrativas, e passamos a buscar outros modos de se cultivar e realizar o caminho que não envolvam o eu. Esses são usos hábeis do não-eu, que adquirimos na prática ao longo do caminho, após termos maestria suficiente sobre os usos hábeis do eu que foram ressaltados nesse artigo.

\section{CONSIDERAÇÕES FINAIS}

Os ensinamentos do Buddha apresentados ao longo dos suttas não são logicamente fechados; quer dizer, não se constituem em um sistema baseado em axiomas e princípios primeiros a partir dos quais se deduz verdades que se seguem logicamente desses princípios. Ao invés disso, é um sistema soteriologicamente fechado, isto é, um método coerente de libertação espiritual onde cada ensinamento contribui para este fim e está inserido em um contexto soteriológico subordinado à realização das tarefas das quatro nobres verdades. O que ocorre muitas vezes ao lermos os suttas é que podemos encontrar diversas versões diferentes de anattā, ensinadas em diferentes contextos para diferentes interlocutores. Diferente de um sistema logicamente fechado, em um sistema soteriologicamente fechado pode ocorrer que um determinado ensinamento seja útil para um praticante em determinado estágio do 
caminho, enquanto o mesmo ensinamento não será útil para outro praticante em um estágio diferente. E como os suttas não seguem nenhuma ordem específica, os ensinamentos destinados aos praticantes de estágios mais avançados do caminho se encontram misturados aos ensinamentos mais básicos, destinados aos iniciantes no caminho Buddhista.

Quando aprendemos sobre anattā como o abandono total do eu em todas as suas dimensões, estamos diante de um ensinamento que diz respeito aos estágios finais da prática. Se isto não for cuidadosamente ressaltado, corre-se o risco de tomar esse ensinamento como dado antes da hora, o que pode ser prejudicial para a realização do caminho. Afinal de contas, se não há eu, como pode haver um agente que age, e um recipiente para os frutos destas ações? Mas como vimos ao longo desse artigo, esse modo de ver as coisas está invertido: ao invés de tomarmos anattā como dado e nos perguntarmos como o kamma é possível, tomamos o kamma como elemento central e inserimos anattā como um tipo de ação ${ }^{4}$. Como tal, é passível de ser hábil ou inábil, e pode ser desenvolvida e aprimorada pela experiência.

Aos que ainda estão no início do caminho Buddhista, é fundamental ressaltar que há espaço para o eu na realização desse caminho, desde que tenhamos uma compreensão clara do propósito final em nome do qual o eu será utilizado. Foi exatamente isso o que procurei mostrar nesse artigo. Utilizado desta forma, sem apego ou reificação, e com sabedoria e discernimento, o "eu" poderá ser uma ferramenta poderosa para o seu próprio fim.

\section{REFERÊNCIAS}

DENNETT, Daniel. The Self as a Center of Narrative Gravity. In: KESSEL, F.; COLE, P; JOHNSON, D (org.). Self and consciousness: multiple perspectives. Hillsdale, NJ: Erlbaum, 1992.

MAHATHERA, Nyanatiloka. The Buddha's teachings of egolessness: anattā. Colombo: The Word of the Buddha Pub. Committee, 1957, p. 103-115.

THĀNISSARO BHIKKHU. Skill in questions. Valley Center, CA: Metta Forest Monastery, 2010. 
THĀNISSARO BHIKKHU. Selves and not-self: The Buddha's teachings on anattā. Valley Center, CA: Metta Forest Monastery, 2011.

THĀNISSARO BHIKKHU. Handful of Leaves: an anthology from the Sutta Pițaka. Valley Center, CA: Metta Forest Monastery, 2014. 